\title{
Brasil-China: uma integração produtiva virtuosa?
}

Valéria Silva Mortari ${ }^{1}$

Caroline Giusti de Araújo ${ }^{2}$

Antônio Carlos Diegues 3

\begin{abstract}
Resumo: Este artigo objetiva analisar os benefícios bilaterais gerados na relação comercial entre Brasil e China. Entende-se que as transformações estruturais vivenciadas nas últimas décadas são fatores condicionantes dos resultados. O método utilizado foi a análise insumo-produto pelo multiplicador interregional, que permite mensurar o estimulo direto e indireto gerado pela produção setorial chinesa sobre a produção brasileira (e vice-versa) entre 2000 e 2014. Os resultados mostraram que os estímulos promovidos pela produção brasileira sobre a chinesa são maiores. Dessa forma, entende-se que há uma assimetria no posicionamento das economias em benefício à asiática, dada pela falta de articulação de políticas no Brasil.

Palavras-chave: Brasil, China, Integração comercial, Insumo-produto.
\end{abstract}

Classificação JEL: $\mathrm{O}_{25}$; 667 .

Brazil-China: A virtuous productive integration?

\begin{abstract}
This paper aims to analyze the bilateral benefits generated in the commercial relationship between Brazil and China. It is understood that the structural transformations experienced in the last decades are conditioning factors to the results. The method used was the input-output analysis by the interregional multiplier, which allows the measurement of direct and indirect stimulus generated by the Chinese sectorial production over the Brazilian production and vice versa, between the years 2000 and 2014. Results showed that the stimulus promoted by the Brazilian production on the Chinese is larger. Thus, it is understood that there is an asymmetry in the positioning of the economies to benefit the Asian one due to the lack of policies articulation in Brazil.
\end{abstract}

Keywords: Brazil, China, Trade integration, Input-ouput.

\section{Introdução}

Nos últimos anos, o fortalecimento do processo de globalização ampliou a complexidade das relações entre nações ao intensificar os fluxos comerciais e financeiros, o que refletiu na crescente interdependência entre as economias em nível global. Nesse cenário, com o acirramento da competição externa, as empresas deixaram de delimitar suas atividades a um território nacional específico tornando-se uma rede de negócios globalmente dissolvida, de maneira que cada região passou a se especializar em aspectos particulares da produção. Essa estratégia de fragmentação global da produção configurou o que ficou conhecido como Cadeias Globais de Valor (CGV). Nesse contexto, intensificouse o comércio interindustrial para além das fronteiras nacionais, isto é, as economias passaram a

\footnotetext{
1 Doutoranda no Programa de Pós Graduação em Desenvolvimento Econômico da Universidade Federal do Paraná. Email: mortarivaleria@gmail.com

2 Doutoranda em Política Científica e Tecnológica - DPCT-IG/UNICAMP. Email: carolgiustiaraujo@gmail.com

3 Núcleo de Economia Industrial e da Tecnologia. Professor do Instituto de Economia - UNICAMP. Email: diegues@unicamp.br
} 
incorporar, de forma crescente, bens intermediários importados no seu processo produtivo, de modo que o efeito multiplicador da produção transbordasse para diversos países ao redor do mundo.

No que diz respeito à importância das relações comerciais entre o Brasil e a China nos anos 200o, nota-se que estas apresentaram um crescimento superior à elevação do comércio entre o Brasil e o mundo. No entanto, a inserção de cada um dos países nas CGV se dá de maneira distinta, isto é, de modo assimétrico e hierárquico, em benefício do país asiático. Ainda que a pauta chinesa seja caracterizada pela baixa complexidade tecnológica, o país tem promovido esforços significativos em direção a mudanças na sua estrutura produtiva, enquanto no Brasil se discute a crescente reprimarização da pauta exportadora, a desindustrialização e o processo de especialização regressiva. A diferença observada na inserção internacional pode ser atribuída às decisões de políticas econômicas implementadas nos dois países ao longo das últimas décadas, as quais repercutem na forma pela qual cada um se insere no comércio internacional, assim como determinam as sinergias entre ambos.

Considerando essa nova divisão internacional do trabalho, este artigo tem como objetivo analisar a integração produtiva entre as economias brasileira e chinesa. Nesse sentido, busca-se compreender a complementaridade produtiva existente entre as duas economias em termos de bens intermediários ao processo produtivo e, com isso, ressaltar não apenas a dimensão quantitativa, mas também a qualitativa desse processo de integração regional. O método utilizado foi o multiplicador regional, obtido a partir da matriz insumo-produto. Esse método permite mensurar qual o impacto direto e o indireto sobre o valor bruto da produção (VBP) do Brasil para cada dólar produzido por um determinado setor chinês, seja industrial ou de serviços, e o quanto um dado setor brasileiro, ao produzir, gera de transbordamento produtivo para a economia chinesa.

Pôde-se também avaliar qual dos países é o mais beneficiado sob a perspectiva tecnológica e, a partir da análise da mudança na dinâmica tecnológica nos fluxos do comércio de bens intermediários, a produção entre os dois países nos anos 2000 e 2014. Dessa maneira, foi possível averiguar o quanto um país depende da transferência tecnológica de seu parceiro comercial, a fim de realizar suas atividades produtivas. Por fim, intenta-se, qualitativamente, entender como as políticas econômicas de cada país podem influenciar nesse processo.

Este trabalho está estruturado em quatro seções, além desta introdução. A primeira busca discutir a maneira pela qual as economias chinesas e brasileiras têm se desenvolvido nos últimos anos, com ênfase no setor industrial e nas mudanças estruturais recentes, assim como na relação comercial entre os dois países-um tópico que visa conciliar os antecessores e embasar os objetivos do trabalho. A segunda seção diz respeito ao detalhamento do método de análise insumo-produto regional utilizado para investigar a complementaridade produtiva entre os dois países. A terceira consiste na análise dos resultados alcançados pela aplicação do método. Por fim, na última seção encontram-se as considerações finais.

\section{Referencial Teórico}

\subsection{Desenvolvimento industrial chinês}

O processo de fragmentação internacional da produção engendrou o que ficou conhecido como cadeias globais de valor, as quais inseriram na dinâmica global, diversos países em desenvolvimento. Estes se beneficiaram das estratégias utilizadas pelas grandes empresas em deslocar as responsabilidades e atividades produtivas de menor valor agregado para países terceiros, dinamizando a economia dos últimos, de forma que a inserção diferenciada nessa conjuntura significa profundas transformações na estrutura produtiva e ganhos nos fluxos de comércio. No entanto deve-se destacar que a capacidade de apropriação do valor adicionado se dá de modo hierárquico e assimétrico ao longo de toda a cadeia e entre os países que a compõem.

Gereffi (2009) destaca que os esforços realizados pela China proporcionaram profundas transformações estruturais no país. Estas foram iniciadas em 1978 e intensificadas na medida em que o país passou a participar da Organização Mundial do Comércio (OMC) nos anos 200o, abrindo sua economia e conquistando parcelas significativas do comércio internacional continuamente. Esse 
processo de transformação estrutural foi desenvolvido, articulado e coordenado pelo Estado, que, entre outras políticas desenvolvimentistas, realizou diversas políticas de atração de Investimento Direto Externo (IDE). Além disso, o autor destaca que o modelo de desenvolvimento chinês realizou esforços significativos para além da dimensão produtiva, em áreas intensivas do conhecimento. Assim, o país se tornou um dos principais receptores de investimentos em pesquisa e desenvolvimento (P\&D), que, concomitante à crescente mão de obra especializada e de baixo custo, tem viabilizado um caminho para uma inserção diferenciada no comércio internacional.

Segundo Masiero e Coelho (2014), o governo promoveu uma política industrial seletiva, que visava estimular setores estratégicos como os de alta tecnologia e capital-intensivos por intermédio de um planejamento industrial específico, que objetivava promover o desenvolvimento nacional. Destaca-se que havia uma complementaridade entre as políticas industriais, macroeconômicas e comerciais, que permitiu uma inserção internacional subordinada às necessidades locais. O Estado regulou o timing de liberalização da conta capital, privilegiando o IDE em detrimento dos capitais de curto prazo, e promoveu o fortalecimento do sistema bancário do setor público, tornando-o capaz de fornecer e controlar a concessão de crédito para a realização dos investimentos na área industrial.

Além disso, houve a criação das Zonas Econômicas Especiais (ZEEs), que visavam estimular a produtividade industrial. Essas áreas foram selecionadas pelo governo chinês para a entrada do capital externo na forma de investimentos de longo prazo. Percebe-se que essas províncias foram as maiores responsáveis pelo desenvolvimento industrial e financeiro da China. A criação das ZEEs teve ainda uma perspectiva estratégica de absorção tecnológica de outros países via atração de empresas multinacionais. A forma de entrada dessas empresas se deu por modelo de joint venture, no qual eram obrigadas a se associarem às empresas chinesas, garantindo, além da atração, a absorção do know-how.

Módolo e Hiratuka (2012) demonstraram que o crescimento acelerado da economia chinesa nas últimas décadas produziu impactos em diversos países ao redor do mundo, principalmente pela via do comércio, ao abrir um novo mercado em forte expansão, tanto via consumo de bens finais como de bens intermediários que complementam a estrutura produtiva do país. No entanto o posicionamento da China no mercado internacional tem outro efeito, que é o de deslocar as exportações de outros países desenvolvidos e em desenvolvimento para terceiros. Os autores verificaram um padrão em que as economias em desenvolvimento se mostraram mais beneficiadas que as economias desenvolvidas pela crescente inserção chinesa no abastecimento do mercado global.

Segundo Gereffi (2007), a China se estabeleceu rapidamente como principal fornecedora de produtos intensivos em trabalho nas CGV, alcançando vantagens de custos, que o autor caracteriza como praticamente insuperáveis, nos bens de consumo. Dessa forma, os produtos chineses têm se estabelecido pelo mundo, abastecendo não apenas mercados emergentes, mas também economias desenvolvidas como os Estados Unidos. Destaca-se ainda que as mudanças ocorridas na estrutura produtiva chinesa nos últimos anos têm permitido ao país averiguar uma ascensão em suas exportações de bens com maior conteúdo tecnológico.

Morais (2012), Nonnemberget. al. (2008) e Nonnemberg \& Mesentir (2012) afirmam que a China tem aumentado o conteúdo doméstico na indústria de alta tecnologia e, portanto, está cada vez menos associada a um montador final na cadeia produtiva global. Os autores avaliaram que o país não se tornou mais competitivos apenas em bens finais, intensivos em mão de obra barata, mas também na produção de partes, peças e componentes, que requerem maior qualificação do trabalho. Analisa-se também que o processo de escalada tecnológica do país não poderia ocorrer sem os anos de investimento em educação e sem um esforço para tornar as empresas capazes de adotar e ajustar o conhecimento estrangeiro. Eles concluem, dessa maneira, que a China está avançando para elos mais nobres na hierarquia das CGV.

Corrêa, Pinto e Castilho (2016) também identificaram que o país aumentou a sua participação nas manufaturas intensivas em tecnologia, o que significa que o desempenho apresentado na perspectiva das CGV tem lhe conferido a capacidade de realizar o que se denomina upgrading de cadeia. Assim, a China tem migrado, de modo gradual, de setores mais intensivos em mão de obra para a produção de bens que incorporam maior nível tecnológico e, portanto, maior valor adicionado. Nesse movimento de ascensão nas cadeias, Nonnemberg et. al (2008) observaram que esse fenômeno está conjuntamente 
associado à posição geográfica do país, que facilita o estabelecimento de relações de comércio mutuamente benéficas com outros países asiáticos como Japão, Coréia do Sul e Taiwan, e que lhe propicia uma determinada complementaridade produtiva.

Destaca-se, por fim, que esse movimento de inserção internacional acirrou de modo proeminente a concorrência com os players tradicionais, definindo uma "nova" geografia econômica. Além disso, percebe-se um modelo capaz de gerar linkages, leverage, learning e indigenous innovation (MASIERO E COELHO, 2014). Ou seja, um modelo estruturado para fazer com que o "made in China" seja desassociado da baixa qualidade e da capacidade de inovação, já que os produtos produzidos no país passaram a contar com aprendizado rápido e articulado aos demais setores e empresas internacionais e também com o desenvolvimento endógeno de inovações.

\subsection{Desenvolvimento industrial brasileiro na atualidade}

Os anos 1990 marcaram na economia brasileira um período no qual as decisões de políticas econômicas repercutiram direta e indiretamente sobre a estrutura produtiva industrial. A combinação de abertura comercial, câmbio sobrevalorizado e taxa de juros elevada sem uma correspondente política industrial propriamente articulada e coordenada engendrou um processo de significativo aumento do coeficiente de penetração de importação na economia, com destaque para setores intensivos em tecnologia e em capital (CARVALHO, 2007), expondo demasiadamente a indústria nacional à concorrência externa. Nesse contexto, "empresas tentaram ajustar-se à concorrência com produtos importados, através de estratégias defensivas de especialização, que com frequência afetaram negativamente a produção local de peças e produtos com mais alto teor tecnológico" (BAUMANN, 1999, p.46).

Nesse sentido, observou-se um movimento de aumento contínuo e generalizado das importações no Brasil, principalmente no que diz respeito a bens intermediários. Isso, por sua vez, refletiu em um processo de substituição de fornecedores internos por externos, processo esse que não se restringiu apenas aos anos 1990, mas se estende à conjuntura atual. Segundo Morceiro, Gomes e Magacho (2014), a parcela de insumos importados apresentou aumento generalizado no período entre 2003 e 2008 , em que aproximadamente $60 \%$ de insumos comercializáveis utilizados na produção são importados, de maneira que a indústria vem perdendo seu peso na contribuição para o crescimento do PIB e na geração de emprego. Essa conjuntura, em que as lacunas da matriz industrial são preenchidas crescentemente por insumos importados, resulta no enfraquecimento dos elos produtivos (MARCONI; BARBI, 2010, FONSECA, 2010, MORCEIRO, 2012, MAGACHO, 2010, 2013, MORCEIRO, et. al, 2014), ou seja, em uma menor interdependência setorial na economia.

Sarti e Laplane (2002), por sua vez, destacaram que, embora o aumento da participação das importações na atividade industrial brasileira tenha permitido uma elevação da eficiência e ganhos significativos na produtividade da indústria doméstica, esses ganhos não se traduziram em um correspondente aumento nas exportações. Com isso, a estrutura produtiva brasileira tem se voltado nas últimas décadas à finalidade de abastecimento do mercado interno, "através da maior presença das empresas estrangeiras como do aumento do conteúdo importado da produção. No Brasil, o processo pode ser caracterizado como de internacionalização do mercado doméstico" (SARTI, LAPLANE, 2002, p. 9o). Assim, entende-se que o cenário descrito acaba por produzir e reproduzir uma estrutura produtiva subordinada no âmbito da economia internacional.

Segundo Sarti e Hiratuka (2016), o Brasil, nos anos 200o, tornou-se o segundo maior país, dentre o conjunto de países em desenvolvimento, receptor de Investimento Estrangeiro Direto (IED). Arent (2015), no entanto, destaca que os fluxos estrangeiros na esfera produtiva tiveram o efeito de "aprofundar a especialização produtiva nacional na direção de setores intensivos em recursos naturais, commodities industriais e tecnologias do paradigma já superado pelos países centrais e periféricos dinâmicos" (ARENT, p. 52, 2015). Essa configuração engendrou uma estrutura industrial essencialmente especializada, com menor grau de integração local e ainda de ínfima densidade tecnológica (SARTI, HIRATUKA, 2016) 
Segundo Filgueiras (2012), a valorização cambial, concomitante à maior participação da economia chinesa no cenário internacional nos anos 2000, contribuiu para que a competitividade da indústria de transformação brasileira fosse relativamente comprometida, enquanto as commodities agrícolas e minerais assumiram um papel chave para o desempenho das exportações, aumentando inclusive a sua participação no PIB. Assim, para o autor, a persistência desse cenário - câmbio valorizado e efeito China no comércio mundial - viabilizou a configuração de um processo de especialização regressiva na indústria brasileira concomitante à reprimarização da pauta exportadora.

De fato, o estudo de Arent (2015) constata que 74\% da estrutura produtiva industrial brasileira em 2010, diante da nova divisão internacional do trabalho, encontra-se concentrada em commodities agrícolas e na indústria intensiva em mão de obra, enquanto o complexo eletrônico corresponde a apenas $2,4 \%$ do parque industrial brasileiro. Esse perfil industrial é reflexo da própria estrutura de investimento produtivo brasileiro, que entre 1996 e 2010 apresentou taxas de crescimento nas atividades voltadas ao petróleo $(456 \%)$ e commodities agrícolas (250\%), enquanto essa mesma variável no mesmo intervalo de tempo cresceu $1 \%$ no segmento de manufaturados de média-alta e alta tecnologia (AREND, 2015).

É interessante ressaltar que o Brasil elevou a sua participação nas exportações mundiais de modo relativamente lento, saindo de um patamar de o,9\% em 1995 para 1,3\% em 2013, sendo que o principal responsável por esse desempenho está relacionado à comercialização de produtos primários (Pinheiro, et. al. 2015). O mesmo não se pode dizer em relação à sua atuação no comércio internacional como importador, pois a participação nas importações mundiais se eleva de 0,5\% em 1990 para 1,45\% em 2013, tendo sua pauta concentrada em produtos industrializados (SARTI, HIRATUKA, 2016). Entende-se, assim, que o Brasil vivencia um processo desequilibrado e assimétrico quanto à sua inserção internacional, seja ela de natureza produtiva ou comercial.

Com base nesse arcabouço, Diegues e Rossi (2016) avaliaram que entre 2000 e 2010 surgiu um novo padrão de organização e de acumulação na esfera industrial brasileira. Esse novo padrão da origem, que os autores denominam de "doença brasileira", representa um movimento de reconfiguração estrutural da indústria que se direciona à especialização regressiva e à desindustrialização, em paralelo a estratégias que garantem a acumulação do capital industrial. A indústria brasileira passou a reduzir gradativamente o conteúdo local na produção e a importar insumos produtivos, ampliando sua integração como importadora nas CGVs. Concomitante a esse processo, os autores notaram uma elevação da massa de lucro do setor industrial no período analisado em empresas com 30 ou mais ocupados, ou seja, identificou-se uma nova forma de acumulação de capital que permite às empresas não se prenderem à esfera da produção. Observa-se, assim, que, contrariando o esperado em um processo de desenvolvimento industrial, a apreciação cambial leva a um aumento da rentabilidade e da lucratividade na indústria.

Bresser-Pereira e Marconi (2010) avaliaram que há sinais da ocorrência da doença holandesa na economia brasileira, isto é, de um processo em que apreciação cambial resulta na valorização dos preços das commodities e dos recursos naturais, produtos em que o país apresenta vantagem comparativa no mercado internacional. Esse cenário leva à especialização da atividade produtiva nesses bens, fazendo com que o país possa ter seu processo de industrialização interrompido.

Os efeitos das políticas macroeconômicas brasileiras nas últimas décadas e a nova configuração global da produção têm produzido impactos significativos sobre a estrutura industrial local. Nessa perspectiva, o país encontra diversos obstáculos e dificuldades para se inserir competitivamente no cenário internacional da produção. Esse processo tem refletido em crescentes desarticulações das cadeias produtivas internas e na pauta de importação, que está fortemente concentrada em bens intermediários de maior intensidade tecnológica, enquanto a pauta de exportação concentra-se em produtos primários. Logo, as deficiências estruturais, somadas ao novo dinamismo do comércio internacional, estão aumentando a distância do desenvolvimento industrial brasileiro em relação às economias desenvolvidas e às economias emergentes, as quais têm conseguido se inserir virtuosamente nesse processo, como a China. 


\subsection{Integração produtiva Brasil-China}

A nova configuração mundial da produção promoveu um aumento significativo da interdependência entre as economias, sendo a China uma das que mais se beneficiou desse movimento, juntamente com as economias asiáticas (HIRATUKA, SARTI, 2010). Dessa maneira, o estímulo à produção de um setor industrial em determinado país deixa de promover spillovers de renda e emprego apenas (ou em maior medida) na economia doméstica. Devido à maior integração produtiva e à interligação internacional da atividade econômica, esses transbordamentos não se restringem às fronteiras nacionais, mas se espraiam para diversos países que complementam a estrutura produtiva do primeiro. Nesse tópico, busca-se identificar, por meio de artigos especializados, como se dá a integração produtiva entre a China e o Brasil, objeto de análise deste estudo.

Ressalta-se que as relações comerciais Brasil e China representam uma nova configuração da integração regional, isto é, o Brasil já apresentava um padrão de especialização comercial com a América Latina, a União Europeia, os EUA e a própria Ásia. Logo, o estreitamento de laços e as interações tecnológicas são parte de uma nova geografia econômica que tem se estabelecido a partir dos anos 2000, com o avanço da economia chinesa. De Negri (2005) apresenta o desenho da integração regional brasileira por tipo de empresa (nacional e estrangeira) e por tecnologia (categorizadas pela intensidade tecnológica dos setores) para os anos 2000-2003.

O panorama encontrado pela autora foi de que o Brasil era capaz de exportar produtos de alta intensidade tecnológica para mercados como o norte-americano, mas não o fazia para o mercado europeu, para o qual o país exportava essencialmente commodities e importava produtos mais intensivos em tecnologia. Já a América Latina tinha uma importância maior como destino das exportações para as empresas multinacionais instaladas no Brasil (32\% do total de suas exportações) que para as nacionais (15\%), relação inversa à encontrada para as importações. O saldo comercial brasileiro com os países desenvolvidos, de forma geral, foi sustentado essencialmente por commodities e por produtos intensivos em mão de obra e recursos naturais para o período analisado. A região asiática, por sua vez, não representava um mercado significativo em termos de destino das exportações e das importações e já apresentava um padrão de relações tecnológicas caracterizado por exportações de baixa intensidade tecnológica e importações diluídas em todos os segmentos industriais.

Altemani (2010) salienta que em meados de 2009 a China tornou-se o principal parceiro comercial do Brasil, tanto em termos de destinos das suas exportações como em relação à origem de suas importações. Porém o autor salienta que essa inter-relação ocorre de forma assimétrica, na medida em que as exportações brasileiras estão concentradas em commodities, enquanto as importações estão ligadas a bens industrializados. Nesse sentido, a capacidade de transbordamentos interssetoriais de um país em relação ao outro se mostra desigual.

Quanto ao posicionamento do Brasil em relação à China, Becard (2011) coloca como ponto principal a criação em 2008 da "Agenda China", cujo objetivo era dinamizar a relação bilateral entre os países em termos de comércio, investimentos e aprendizado tecnológico. Nessa agenda, o Brasil colocou como uma de suas prioridades a elevação do conteúdo tecnológico de suas exportações, com o intuito de equilibrar, de forma qualitativa e quantitativa, a balança comercial entre os países. No entanto não foi possível até então observar os frutos dessa agenda; pelo contrário, observa-se um movimento de ascensão da China no mercado mundial, com ganhos de participação inclusive em áreas com maior valor agregado, enquanto a indústria brasileira passa por um processo de desindustrialização e especialização regressiva, o que dificulta o alcance dos objetivos estabelecidos nessa agenda.

Entende-se, pelo trabalho de Dias et. al (2016), que o comércio exterior brasileiro como um todo vem sofrendo alterações nas últimas décadas, de tal forma que o comportamento da balança comercial brasileira em relação à China é o mesmo quando se analisa a relação do Brasil com o resto do mundo. Os autores mostram que, pela vertente do mapa da complexidade, o Brasil, ao longo dos últimos anos. Tem apresentado a característica de importador de conhecimento, na medida em que se observa uma crescente especialização em produtos como a soja, o petróleo bruto e o minério de ferro. Ao entrar na abordagem de CGV, esse cenário não se altera, ou seja, o Brasil tem se inserido nessa dinâmica mundial da produção como um fornecedor de bens intermediários de baixo valor adicionado. 
A esse respeito, destaca-se Cano (2012), ao analisar a formação de uma nova divisão internacional do trabalho, com elevada produtividade e câmbio desvalorizado, fazendo com que as relações comerciais entre China e América Latina se configurassem como centro-periferia. Essa divisão do trabalho é caracterizada pela pauta exportadora chinesa, concentrada em produtos manufaturados, e pela pauta importadora em bens primários. O autor mostra ainda que houve uma queda nas exportações manufatureiras do Brasil para a China de 8o,5\% em 1990 para 22,5\% em 2008.

Com isso, espera-se, pela ótica tecnológica, que o efeito de transbordamento da economia brasileira sobre a chinesa tenha uma magnitude superior quando se avalia a relação inversa. Nessa perspectiva, o trabalho de Dias et. al (2016) encontrou que a relação entre esses países se aprofundou ao longo de 1995 e 2011, e por meio da relação de compra e venda entre eles foi possível mostrar que o efeito de geração de emprego entre as economias foi favorável para ambas, como pode ser visto:

\footnotetext{
Entretanto, a economia chinesa apresentou uma magnitude muito maior quando confrontada com o Brasil, os requerimentos diretos e indiretos (influência da demanda de insumos chineses pela economia brasileira) mais que dobraram, mas a propagação interna (readequação da economia chinesa) cresceu muito mais. A direção da relação quando a relação é invertida, ou seja, a influência da economia chinesa sobre a brasileira apresenta ganhos, porém em uma magnitude muito menor. [...] a intensificação da relação entre as economias brasileiras e chinesas geram criação de empregos em ambas, porém essa criação foi muito maior para a economia chinesa. Isso talvez possa ser explicado pela diferença de pautas de exportações e importações das economias, gerando assim impactos distintos. (DIAS, et. al. 2016, p.15)
}

Entende-se, assim, que o Brasil tem assumido uma posição subordinada no que diz respeito à sua relação comercial com a China. O aumento significativo da demanda chinesa por produtos agrícolas e sua extensa e crescente oferta de produtos manufaturados, inclusive de alta tecnologia, tem significado para o Brasil a concentração da pauta exportadora e a desarticulação das cadeias produtivas industriais internas, dada a incapacidade de o país competir com os produtos chineses. Aponta-se, dessa forma, para mudanças estruturais profundas na economia brasileira no longo prazo (STURGEON, 2013).

Essa análise pode ser vista no Gráfico 1, através das diferenças de participação das exportações industriais chinesa e brasileira como percentual das exportações totais dos países em termos de comércio bilateral. Nota-se que, embora o Brasil apresente um volume elevado de exportações para a China, estas são fortemente dependentes dos setores baseados em recursos naturais, ou seja, o país apresenta uma elevada concentração na sua pauta de exportação em detrimento de setores considerados mais dinâmicos ou de maior conteúdo tecnológico. $\mathrm{O}$ mesmo não é verificado quando se observam as exportações da China para o Brasil, pois o fluxo observado nesse caso apresenta um maior grau de diversificação, além de ter maior percentual de exportação para o Brasil nos setores categorizados como diferenciados e intensivos em escala, como pode ser visto no Gráfico 1. Isso, por sua vez, permite ao país melhores termos de troca na relação bilateral estudada. 
Gráfico 1: Exportações industriais da China para o Brasil (esquerda) e do Brasil para a China (direita) de 2001 a 2018

Percentual das exportações de todos os setores da economia bilateral
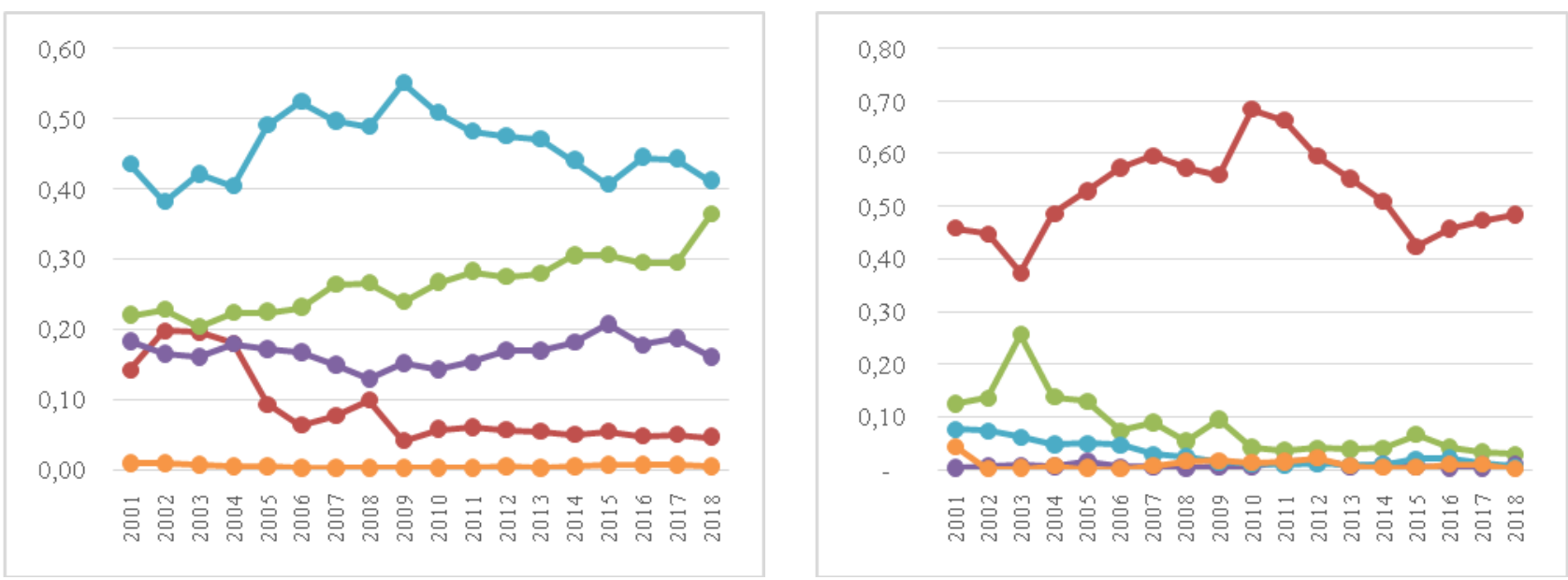

$\rightarrow$ Baseada em recursos naturais $\multimap$ Intensiva em escala $\multimap$ intensiva em trabaltho $\rightarrow$ Diferenciada $\multimap$ Baseada em ciência

Fonte: Elaboração própria a partir de dados disponibilizados pelo TRADEMAP

Pode-se dizer, portanto, que existe uma disparidade na relação comercial Brasil-China, dado que em 2011 a exportação de produtos primários correspondeu a 83\% do total exportado para a China, enquanto no mesmo ano produtos manufaturados intensivos em P\&D responderam por $20 \%$ do total das importações provenientes do país asiático (HIRATUKA, SARTI, 2016). Esse movimento é reflexo do modo de inserção da economia chinesa, que se constitui como uma importante demandante de commodities, ao mesmo tempo em que se firma como uma grande produtora de manufaturas. Com isso em vista, é interessante ressaltar Hiratuka e Sarti (2016):

(...) que a forma como a economia brasileira tem se articulado com a economia chinesa, sobretudo por meio dos fluxos de comércio, [...], vem, por um lado, oferecendo perspectivas mais favoráveis de crescimento macroeconômico. Por outro lado, tais fatores vêm criando obstáculos ao nível da estrutura produtiva, muito em função de um potencial deslocamento da produção doméstica em vários setores, justamente pela concorrência com a produção da indústria manufatureira brasileira. (HIRATUKA, SARTI, p.84, 2016)

Nessa perspectiva, Diegues e Rossi (2016) avaliaram que o arcabouço político-econômico atual permite observar o surgimento de uma indústria doméstica brasileira com uma dinâmica competitiva e de acumulação, distinta da que caracteriza os países asiáticos, que conseguiram promover sua inserção internacional virtuosa pela via da exportação de manufaturados. Dessa forma, entende-se que a distinção na dinâmica de integração comercial entre os dois países apresentados nessa seção, principalmente no que diz respeito às diferenças tecnológicas que caracterizam o saldo comercial bilateral das duas economias, embasa a importância dos objetivos deste trabalho de analisar a integração produtiva entre eles por meio do multiplicador regional.

\section{Metodologia}

A teoria do insumo-produto foi desenvolvida pelo economista Leontief na década de 1930. Leontief conseguiu retratar a economia em determinado período, captando as relações contemporâneas entre os setores da economia como se fossem partes de um único organismo. (GUILHOTO, 2004). As relações econômicas assim sintetizadas constituem a matriz de insumo-produto (MIP). 
A MIP trata da descrição da economia em termos de circulação, retratando-a como um sistema integrado de fluxos e de transferências de insumos e produtos entre setores. Cada um dos setores produz bens e serviços que podem ser utilizados no consumo intermediário por outros setores, ou consumidos como demanda final. Por sua vez, esse mesmo setor demanda insumos de outros setores para sua produção. Assim, as vendas realizadas por um setor constituem-se em compras de outros. O segundo setor, percebendo que sua demanda aumentou, comprará mais fatores de outros setores, e assim por diante. Dessa forma, a MIP reflete a complexidade da propagação em cadeia pelo setor produtivo da decisão de compra ou investimento (MILLER; BLAIR, 2009).

A MIP é composta pela conta de produção global e é dividida em três partes. A primeira retrata a demanda intermediária, isto é, as transações de compra e venda entre os setores produtivos. A segunda é composta pelo valor adicionado, que compreende a remuneração dos fatores e o excedente bruto operacional, os impostos e subsídios incidentes sobre a produção e as importações. A demanda final, a terceira parte da MIP, é composta pelo consumo das famílias e do governo, da formação bruta de capital e das exportações. Uma MIP ilustrativa é apresentada na Figura 1, em que 1 e 2 são setores produtivos, Fi é a demanda final para cada região e setor, VA é o valor adicionado e Xi representa o total da produção. As variáveis Xij representam o consumo intermediário do insumo i na produção do bem j.

As linhas representam as vendas dos setores para os demais segmentos internos à economia (MM ou LL) e as vendas para outras regiões (LM ou ML), enquanto as colunas representam o quanto um determinado setor, para produzir um bem final X, demanda (compra) de insumos intermediários internamente (MM ou LL), de outra região (LM ou ML) e do resto do mundo, e ainda o quanto esse setor paga de impostos e remunera os fatores de produção.

Figura 1: Matriz Insumo Produto Inter-Regional Representativa

\begin{tabular}{|c|c|c|c|c|c|c|c|c|}
\hline & & & \multirow{2}{*}{\multicolumn{2}{|c|}{ Região L }} & & & & \\
\hline & & & & & \multicolumn{2}{|c|}{ Região M } & & \\
\hline & & & \multicolumn{2}{|c|}{ Setores } & \multicolumn{2}{|c|}{ Setores } & & \\
\hline & & & 1 & 2 & 1 & 2 & DF & DT \\
\hline \multirow{2}{*}{ Região L } & \multirow{2}{*}{ Setores } & 1 & $\mathrm{X}_{11}^{\mathrm{LL}}$ & $\mathrm{X}_{12}{ }^{\mathrm{LL}}$ & $\mathrm{X}_{11}^{\mathrm{LM}}$ & $\mathrm{X}_{12}{ }^{\mathrm{LM}}$ & $\mathrm{F}_{1}^{\mathrm{L}}$ & $\mathrm{X}_{1}^{\mathrm{L}}$ \\
\hline & & 2 & $\mathrm{X}_{21}^{\mathrm{LL}}$ & $\mathrm{X}_{22}^{\mathrm{LL}}$ & $\mathrm{X}_{21}{ }^{\mathrm{LM}}$ & $\mathrm{X}_{22}{ }^{\mathrm{LM}}$ & $\mathrm{F}_{2}{ }^{\mathrm{L}}$ & $\mathrm{X}_{2}{ }^{\mathrm{L}}$ \\
\hline \multirow{2}{*}{ Região M } & \multirow{2}{*}{ Setores } & 1 & $\mathrm{X}_{11} \mathrm{ML}$ & $\mathrm{X}_{12} \mathrm{ML}$ & $\mathrm{X}_{11} \mathrm{MM}$ & $\mathrm{X}_{12} \mathrm{MM}$ & $\mathrm{F}_{1}^{\mathrm{M}}$ & $\mathrm{X}_{1}^{\mathrm{M}}$ \\
\hline & & 2 & $\mathrm{X}_{21} \mathrm{ML}$ & $\mathrm{X}_{22} \mathrm{ML}$ & $\mathrm{X}_{21} \mathrm{MM}$ & $\mathrm{X}_{22} \mathrm{MM}$ & $\mathrm{F}_{2} \mathrm{M}$ & $\mathrm{X}_{2}{ }^{\mathrm{M}}$ \\
\hline & & Import. do resto do mundo & $\operatorname{Im}_{1}^{\mathrm{L}}$ & $\operatorname{Im}_{2}{ }^{\mathrm{L}}$ & $\operatorname{Im}_{1}{ }^{\mathrm{M}}$ & $\operatorname{Im}_{2}{ }^{\mathrm{M}}$ & & \\
\hline & & Impostos Líquidos & $\mathrm{T}_{1}^{\mathrm{L}}$ & $\mathrm{T}_{2}{ }^{\mathrm{L}}$ & $\mathrm{T}_{1}^{\mathrm{M}}$ & $\mathrm{T}_{2}{ }^{\mathrm{M}}$ & & \\
\hline & & VA & $\mathrm{W}_{1}^{\mathrm{L}}$ & $\mathrm{W}_{2}^{\mathrm{L}}$ & $\mathrm{W}_{1}^{\mathrm{M}}$ & $\mathrm{W}_{1}^{\mathrm{M}}$ & & \\
\hline & & VBP & $\mathrm{X}_{1}^{\mathrm{L}}$ & $\mathrm{X}_{2}^{\mathrm{L}}$ & $\mathrm{X}_{1}^{\mathrm{M}}$ & $\mathrm{X}_{2}{ }^{\mathrm{M}}$ & & \\
\hline
\end{tabular}

Tendo por base a matriz de consumo intermediário, pode-se obter a matriz de coeficientes técnicos, os quais são construídos como se segue:

1. Coeficientes intra-regionais (compõem a diagonal principal da matriz):

$$
a_{i j}^{L L}=\frac{x_{i j}^{L L}}{x_{J}^{L}} \text { e } \quad a_{i j}^{M M}=\frac{x_{i j}^{M M}}{x_{J}^{M}}
$$

Em que cada elemento aij expressa o valor do insumo i utilizado na produção do setor j para cada unidade monetária produzida pelo setor $\mathrm{j}$. 
2. Coeficiente técnico inter-regional (compõem as demais diagonais da matriz):

$$
a_{i j}^{M L}=\frac{x_{i j}^{M L}}{x_{j}^{L}} \text { e } a_{i j}^{L M}=\frac{x_{i j}^{L M}}{x_{j}^{M}}
$$

Nesse caso, cada elemento aijML representa a proporção de insumos demandados pelo setor j na região L proveniente do setor i na região $\mathrm{M}$, para cada unidade monetária.

Para cada linha da MIP, tem-se, então, que:

$$
\begin{aligned}
& A^{L L} \hat{X}_{i}^{L}+A^{L M} \hat{X}_{i}^{M}+F^{L}=X^{L} \\
& A^{M L} \hat{X}_{i}^{L}+A^{M M} \hat{X}_{i}^{M}+F^{M}=X^{M}
\end{aligned}
$$

Isolando F em ambas equações chegamos a:

$$
\begin{aligned}
& \left(I-A^{L L}\right) X^{L}-\left(A^{L M} X^{M)}=F^{L}\right. \\
& \left(-A^{M L}\right) X^{L}+\left(I-A^{M M}=F^{M}\right.
\end{aligned}
$$

Em termos matriciais:

$$
\left[\begin{array}{cc}
\left(I-A^{L L}\right) & -A^{L M} \\
-A^{M L} & \left(I-A^{M M}\right)
\end{array}\right]\left[\begin{array}{l}
X^{L} \\
X^{M}
\end{array}\right]=\left[\begin{array}{c}
F^{L} \\
F^{M}
\end{array}\right]
$$

Para encontrar as relações intersetoriais inter/intrarregionais, representadas pela matriz inversa de Leontief, isola-se X:

$$
\left[\begin{array}{l}
X^{L} \\
X^{M}
\end{array}\right]=\left[\begin{array}{cc}
\left(I-A^{L L}\right) & -A^{L M} \\
-A^{M L} & \left(I-A^{M M}\right)
\end{array}\right]^{-1}\left[\begin{array}{l}
F^{L} \\
F^{M}
\end{array}\right]
$$

Logo, o valor bruto da produção X é expresso por X= BF, sendo que B é a matriz inversa de Leontief,

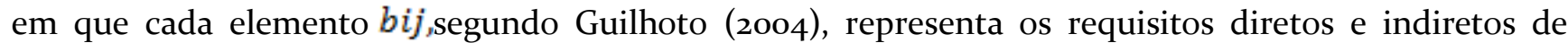
insumos do setor i por unidade de demanda final na produção do setor $\mathrm{j}$ entre as regiões ou dentro de cada região.

Por fim, como o objetivo do trabalho consiste em analisar o efeito de transbordamento de uma região para outra, é necessário que se desagregue primeiramente a matriz $\mathrm{A}$ em

$$
A=\left[\begin{array}{cc}
A^{L L} & 0 \\
0 & A^{M M}
\end{array}\right]+\left[\begin{array}{cc}
0 & A^{L M} \\
A^{M L} & 0
\end{array}\right]
$$

Com isso, o efeito da região L para a região $M$ e vice-versa pode ser capturado pela interação da matriz inversa de Leontief, que reflete as relações intersetoriais intrarregionais, com a matriz de coeficiente técnico inter-regional, que diz respeito à interação produtiva de uma região em relação à outra. Isso se dá da seguinte forma:

$$
\begin{gathered}
M R=\left[\begin{array}{cc}
\left(I-A^{L L}\right)^{-1} & 0 \\
0 & \left(I-A^{M M}\right)^{-1}
\end{array}\right]\left[\begin{array}{cc}
0 & A^{L M} \\
A^{M L} & 0
\end{array}\right] \\
M R=\left[\begin{array}{cc}
I & \left(I-A^{L L}\right)^{-1} A^{L M} \\
\left(I-A^{M M}\right)^{-1} A^{M L} & I
\end{array}\right]
\end{gathered}
$$


Cada elemento $M R_{i j}^{L M}$ representa a seguinte trajetória: se a demanda final do setor j na região $\mathrm{M}$ se elevar em uma unidade monetária, o multiplicador mostra o quanto a produção do setor i na região L aumentará de forma direta e indireta. O mesmo é válido para o efeito transbordamento da região L para a região $M$.

\subsection{Base de Dados}

Foram utilizadas as matrizes de insumo-produto do ano de 2014, disponibilizadas pelo World InputOutput Database (WIOD). As matrizes de insumo-produto e de importação de insumos intermediários estão desagregadas em 56 setores, sendo 20 pertencentes à indústria, o que permite uma análise detalhada da dependência externa da produção industrial chinesa em relação à brasileira e vice-versa. Os dados contidos nas matrizes estão medidos em milhão de dólares, a preços do ano corrente.

Destaca-se que a análise dos resultados será agregada para os setores industriais por tipo de tecnologia, uma taxonomia proposta pela OECD (1997), inspirada na proposta por Pavitt (1984), em que se decompõem os setores industriais em intensivo em trabalho, escala baseado em recursos naturais, ciência e diferenciado. De acordo com Nassif (2008), essa taxonomia relaciona os diferentes tipos de tecnologia ao principal fator responsável pela competitividade dos setores no curto e no longo prazo.

Dessa forma, nos setores intensivos em recursos naturais, o principal fator competitivo é a abundância de recursos naturais; já nos setores intensivos em trabalho, o fator é a mão de obra barata (de baixa e média qualificação) quando comparada a outros países; nos setores intensivos em escala, dados a indivisibilidade tecnológica das plantas produtivas, o fator é a capacidade de produzir em grandes escalas; nos setores diferenciados, refere-se a capacidade de atender diversos padrões de demanda e, por fim, no setor baseado em ciência, o fator é a aplicação de pesquisa científica às tecnologias industriais.

Ainda de acordo Nassif (2008), pode-se inferir que os setores intensivos em escala, diferenciados e baseados em ciência, por possuírem maior tecnologia agregada ao processo produtivo, geram maiores transbordamentos (renda e emprego) e difusão de inovações para a economia. Por outro lado, os setores baseados em recursos naturais e trabalho têm maior capacidade de geração de emprego direto.

\section{Avaliação da integração produtiva}

A Tabela 1 apresenta os resultados encontrados a partir da aplicação do método exposto anteriormente. Assim, os indicadores MR BR-CN 2000 e MR BR-CN 2014 mostram o efeito direto e indireto (em dólar) sobre a produção chinesa para cada dólar produzido pelo Brasil nos setores intensivos em escala, baseados em ciência, em recursos naturais, intensivos em trabalho, diferenciados e pelo setor de serviços. A análise está desagregada entre setores industriais - cada um de acordo com o seu tipo tecnológico - e setor de serviços, no ano de 2000 e 2014. Da mesma forma, os efeitos diretos e indiretos (em dólar) sobre a produção brasileira - observado para cada dólar produzido pelos setores industriais e de serviços chinês para os anos de 2000 e 2014 - estão dispostos nas colunas nomeadas MR CN- BR 2000 e MR CN- BR 2014, respectivamente. Além disso, apresenta-se a taxa de crescimento desses indicadores entre os anos estudados. 
Tabela 1: Efeitos inter-regionais China-Brasil e Brasil-China para os anos de 2000 e 2014 (em dólar) e a taxa de crescimento do efeito no período

\begin{tabular}{c|c|c|c|c|c|c}
\hline & $\begin{array}{c}\text { MR BR-CN } \\
\mathbf{2 0 0 0}\end{array}$ & $\begin{array}{c}\text { MR BR-CN } \\
\mathbf{2 0 1 4}\end{array}$ & $\begin{array}{c}\text { Taxa de } \\
\text { crescimento }\end{array}$ & $\begin{array}{c}\text { MR CN-BR } \\
\mathbf{2 0 0 0}\end{array}$ & $\begin{array}{c}\text { MR CN-BR } \\
\mathbf{2 0 1 4}\end{array}$ & $\begin{array}{c}\text { Taxa de } \\
\text { crescimento }\end{array}$ \\
\hline $\begin{array}{c}\text { Intensivo em } \\
\text { escala }\end{array}$ & 0,0019 & 0,0194 & $916 \%$ & 0,0008 & 0,0025 & $204 \%$ \\
\hline $\begin{array}{c}\text { Baseado em } \\
\text { ciência }\end{array}$ & 0,0013 & 0,0158 & $1133 \%$ & 0,0011 & 0,0011 & $2 \%$ \\
\hline $\begin{array}{c}\text { Baseado em } \\
\text { recursos naturais }\end{array}$ & 0,0010 & 0,0052 & $406 \%$ & 0,0008 & 0,0033 & $333 \%$ \\
\hline $\begin{array}{c}\text { Intensivo em } \\
\text { trabalho }\end{array}$ & 0,0016 & 0,0338 & $2035 \%$ & 0,0006 & 0,0017 & $164 \%$ \\
\hline Diferenciado & 0,0055 & 0,0655 & $1096 \%$ & 0,0006 & 0,0008 & $26 \%$ \\
\hline Serviços & 0,0005 & 0,0043 & $820 \%$ & 0,0007 & 0,0009 & $34 \%$ \\
\hline
\end{tabular}

Fonte: Elaboração pelos autores através de dados disponibilizados pela WIOD

Nota-se, primeiramente, que os efeitos encontrados representam um valor pequeno, por isso optou-se por avaliar a taxa de crescimento do estímulo no período exposto na Tabela 1 . Dessa forma, observou-se que o estímulo promovido pelo Brasil sobre a China via importação de insumos cresceu mais que os estímulos da economia chinesa sobre o Brasil. Além disso, os transbordamentos promovidos pelo Brasil se elevaram independentemente da classificação tecnológica da indústria ou do setor de serviços. Embora o mesmo tenha ocorrido quando avaliado os estímulos da produção chinesa, as taxas de crescimento são discrepantes. Por essa análise, pode-se inferir que, apesar da integração produtiva via comércio internacional ser proveitosa para ambos os países, o processo se dá de maneira desigual em benefício da economia chinesa. Nessa perspectiva, destaca-se ainda que a economia chinesa apresenta requerimento de insumos importados maior quando produz em setores de mais baixo valor agregado.

Além da análise proposta na Tabela 1, pode-se avaliar pelo Anexo 1 quais os setores que, quando estimulados em uma das economias, geram maiores transbordamentos inter-regionais, direta e indiretamente. Nota-se que a China, ao produzir no setor de serviços, não gerou estímulos significativos sobre a economia brasileira nos anos avaliados. Já o Brasil, ao produzir nesse setor, gerou encadeamentos na economia chinesa. Considerando a importância do setor de serviços e a articulação deste aos setores industriais da economia chinesa, entende-se o baixo transbordamento. De forma geral, avalia-se que não há transbordamentos significativos sobre a economia brasileira quando a China eleva sua produção, haja vista que os estímulos não são maiores que um centavo de dólar em todos os setores analisados, tanto em 2000 quanto em 2014.

Por outro lado, destaca-se o elevado transbordamento inter-regional que a economia brasileira promove ao produzir em setores diferenciados sobre a economia chinesa, principalmente no setor de manufatura de computadores, eletrônicos e produtos ópticos em que para cada dólar produzido no setor no Brasil gerou-se um multiplicador inter-regional sobre a economia chinesa de o,19 dólares em 2014. Esse multiplicador foi o que assumiu o maior valor dentre todos os setores e nos dois anos analisados.

Averigua-se que houve um aumento da integração produtiva entre os países, haja vista o maior transbordamento para ambas as economias quando se compara o ano de 2000 e 2014. No entanto, os estímulos gerados pelo Brasil sobre a economia chinesa são maiores que o inverso. Dessa forma, o estudo corrobora as análises que avaliam com cautela o processo de complementaridade bilateral nesse comércio, na medida em que este não tem viabilizado uma relação equilibrada de ganha-ganha. Além 
disso, este estudo procura relacionar esse resultado como fruto das escolhas políticas em termos macroeconômicos e industriais de ambos os países que viabilizam a China saber os benefícios que almeja ao realizar negociações com o Brasil.

Os resultados encontrados na Tabela 1 representam, portanto, um retrato da interação produtiva Brasil e China. Além disso, é possível saber qual o resultado desse processo em termos monetários. Isto é, a partir do valor bruto da produção industrial brasileira e de seu coeficiente de interação regional com a China, pode-se quantificar o impacto da atividade industrial brasileira sobre a economia chinesa para os anos de 2000 e 2014, assim como o impacto da produção chinesa sobre a economia brasileira. Os resultados de tal cálculo encontram-se na Tabela 2; tais resultados não mais refletem o efeito direto e indireto da produção de uma economia sobre a outra, e sim o efeito total, que pode ser interpretado como a expansão verificada na produção da China (Brasil), dado o total produzido em determinado setor produtivo do Brasil (China) em cada ano. É interessante ressaltar aqui que, para realizar a comparação entre os valores observados de 2000 e 2014, é necessário considerar que o montante observado na Tabela 2 abrange duas variáveis que evoluem no tempo, quais sejam: i) o aumento da produção industrial no país (em milhões de dólares); e ii) a mudança no multiplicador regional.

Tabela 2: Efeitos da produção industrial brasileira sobre a chinesa (MR BR-CN) e da chinesa sobre a brasileira (MR CN-BR) para os anos de 2000 e 2014 (em dólar)

\begin{tabular}{c|c|c|c|c}
\hline & \multicolumn{2}{|c|}{ MR BR-CN } & \multicolumn{2}{c}{ MR CN-BR } \\
\cline { 2 - 5 } & $\mathbf{2 0 0 0}$ & $\mathbf{2 0 1 4}$ & $\mathbf{2 0 0 0}$ & $\mathbf{2 0 1 4}$ \\
\hline Intensiva em Recursos Naturais & 244,49 & $7 \cdot 730,96$ & 417,36 & $14.400,63$ \\
\hline Intensiva em Escala & 10,68 & 346,67 & 34,52 & 329,88 \\
\hline Intensiva em Trabalho & 149,15 & $2.868,90$ & 318,67 & $17.175,02$ \\
\hline Diferenciada & 98,57 & $5.273,52$ & 197,12 & $3.513,15$ \\
\hline Baseada em ciência & 232,30 & $8.240,40$ & 209,25 & $2.945,68$ \\
\hline Serviços & 336,24 & $11.509,25$ & 927,56 & $12.089,51$ \\
\hline Total & $1.071,44$ & $35.969,71$ & $2.104,50$ & $50.453,87$ \\
\hline
\end{tabular}

Fonte: Elaboração pelos autores através de dados disponibilizados pela WIOD

Os resultados encontrados na Tabela 2 mostraram que o efeito agregado da China no Brasil é maior que da economia brasileira sobre a asiática, o que era esperado devido à grande variação do PIB chinês no período avaliado. No entanto, é necessário ressaltar em quais tecnologias a China, ao produzir,demonstrou maior impacto sobre a produção brasileira. Nesse sentido, a maior taxa de crescimento dos valores apresentados na Tabela 2 foi na tecnologia intensiva em trabalho, seguida pela intensiva em recursos naturais, e com baixa variação para a tecnologia intensiva em escala. Logo, apesar do efeito da produção industrial chinesa ser comparativamente mais relevante sobre a economia brasileira do que a relação inversa, os encadeamentos mais importantes são dados quando a economia asiática produz em setores de baixa intensidade tecnológica.

Portanto, é interessante destacar que o efeito da produção chinesa sobre a economia brasileira se concentra em setores de baixa tecnologia, ou seja, em setores intensivos em recursos naturais e em trabalho. E não apenas isso.Os produtos pelos quais a produção chinesa depende da importação brasileira são de baixa especificação tecnológica. De fato, a demanda do setor de alimentos e bebidas em relação a importações brasileiras está vinculada ao setor de produção vegetal e animal. Ou ainda, quando o setor de refino de petróleo chinês se expande, o principal produto brasileiro demandado são aqueles ligados à indústria extrativa. Por fim, quanto à indústria intensiva em trabalho, ao produzir produtos têxteis, a principal dependência desse setor em relação à economia brasileira diz respeito ao setor de produção vegetal e animal.

Com relação à economia brasileira, nota-se que as principais variações de estímulos gerados pelo país na economia asiática ao produzir estão nas tecnologias diferenciadas e intensivas em escala, com 
baixa variação na tecnologia intensiva em trabalho. Isto é, em termos dinâmicos, analisa-se que a variação da produção causada pela expansão da economia brasileira tem sido determinada por um padrão de integração assimétrico com a economia chinesa, ou seja, as variações de estímulo da economia latina sobre a asiática se dão, principalmente, quando produz em setores de intensidade tecnológica mais elevada.

Nota-se que quando o Brasil produz computadores, produtos eletrônicos e ópticos, a sua dependência em relação à importação proveniente da China está ligada exatamente a esse setor. Já quando o país produz equipamentos elétricos, a demanda por importações chinesas vincula-se ao setor de equipamentos eletrônicos e metais básicos. Por fim, quando produz máquinas e equipamentos, o Brasil demanda do setor de máquinas, equipamentos e equipamentos eletrônicos do país asiático. Esse quadro enfatiza a tese deste artigo: uma vez que há um processo de integração produtiva benéfica aos dois países no curto prazo, há uma desigualdade de integração tecnológica que tende a promover uma nova forma de subordinação da economia brasileira.

Cunha et al (2011) avaliaram por meio de indicadores de comércio internacional o impacto da presença chinesa na economia brasileira. Os autores buscaram não se desvencilhar dos dois lados do debate, ou seja, que a presença chinesa tende a ser perversa na medida em que pode levar o Brasil a uma concentração produtiva e exportadora em recursos naturais e, com isso, aos problemas apontados pelo pensamento estruturalista. Isto é, há uma tendência ao desequilíbrio externo, cópia dos padrões de consumo com concentração de renda e poder na medida em que os produtos mais intensivos em conhecimento possuem elasticidade-renda superior aos baseados em commodities e recursos naturais, que impacta a estabilidade da balança comercial e, portanto, o crescimento econômico, quando há variações na renda mundial.

Por outro lado, a presença chinesa e sua elevada demanda por recursos naturais promoveram um ciclo de alta nos preços das commodities, que combinados às políticas redistributivas possibilitaram a dinamização do mercado interno no curto prazo. Cunha et al (2011) esclarecem, dessa forma, que a presença chinesa pode oferecer oportunidades ou riscos à economia brasileira e esse limiar estaria mais relacionado às estratégias locais do que ao posicionamento da China no mundo. Nesse aspecto, os autores destacam que, se o ambiente político-econômico for deixado para ser definido pelas circunstâncias, então os resultados tenderão à regressão produtiva e institucional. Por fim, os autores identificaram uma intensificação do comércio bilateral Brasil-China, que tem posicionado o Brasil como fornecedor de commodities. Dessa forma, reiteram o argumento de que se o Brasil não definir suas estratégias de longo prazo e buscar se reposicionar no comércio bilateral, o país estará perdendo espaço no processo decisório do seu desenvolvimento.

Pereira e Neves (2011), por fim, avaliaram que a relação comercial entre China-Brasil tende a ser mais desbalanceada no longo-prazo, tendo em vista que os produtos competem por acesso em outros mercados e atração de investimento externo. Os autores reiteram a análise proposta por este trabalho de que essa relação é fruto de diferentes estruturas institucionais e político-econômicas. Além disso, ressaltam que essas assimetrias tendem a se acentuar através das políticas industriais e de inovação chinesa.

\section{Considerações finais}

Buscou-se, ao longo deste trabalho, compreender a importância e a assimetria das relações comerciais entre China e Brasil. Sabe-se que ambos os países são players importantes nos fluxos de comércio internacional. No entanto as relações bilaterais desenvolvidas ao longo dos anos não têm se configurado como "ganha-ganha" em uma perspectiva de longo prazo. Pelo contrário, nota-se que as articulações política, econômica e institucional têm permitido a China obter vantagens nesses fluxos.

No que diz respeito à economia chinesa, sabe-se que esta intensificou o desenvolvimento de setores com maior dinamismo industrial a partir de meados dos anos 2000, articulando-se ao cenário internacional com uma estratégia going global, ou seja, com uma política industrial focada no processo de inovação em setores-chave, principalmente químico, eletrônico e metal-mecânico. Além disso, percebe-se que o país constituiu um tecido industrial internacionalmente competitivo, atraindo 
empresas internacionais não apenas para produzir na China, mas também para se articular com as empresas nacionais, fazendo com que tecnologias próprias fossem produzidas a partir da economia local.

Por outro lado, o Brasil tem apresentado aumento contínuo e generalizado das importações, de tal maneira que a atividade industrial local tem aumentado gradativamente a sua dependência estrutural do setor externo. Dessa forma, nota-se que a indústria brasileira tem passado por um processo de substituição de fornecedores internos por externos, de modo que parcela importante dos transbordamentos gerados pela produção industrial brasileira seja apropriada pelo setor externo. Alguns autores avaliam que na década de 2000 passou a vigorar no país um processo de desindustrialização, em paralelo à manutenção e ampliação do capital industrial local.

Dado esse conteúdo diferenciado, nota-se pelo método insumo-produto que os estímulos dados pelo Brasil à China ao produzir, via importação de insumos, cresceram mais que os estímulos gerados pela economia chinesa sobre o Brasil. Além disso, os transbordamentos gerados pela economia brasileira cresceram independentemente da classificação tecnológica do setor industrial que o país produz e também no setor de serviços. Embora o mesmo tenha ocorrido quando avaliado os estímulos da produção chinesa, as taxas de crescimento são discrepantes e desfavoráveis à economia brasileira.

Ademais, é importante observar as distintas tecnologias que tiveram maior taxa de crescimento no período, isto é, quando o Brasil aumenta sua produção, percebe-se que a taxa de crescimento do estímulo sobre a economia chinesa no período de 2001 a 2014 é maior nos setores intensivos em trabalho $(2.035 \%)$ e diferenciados (1.096\%). Por sua vez, quando a China eleva sua produção, nota-se que a taxa de crescimento do estímulo sobre a economia brasileira é maior nos setores baseados em recursos naturais (333\%) e intensivos em escala (204\%). Através desta análise, pode-se inferir que a integração produtiva via comércio internacional tem sido desigual em benefício da economia chinesa.

Nesse sentido, destaca-se ainda o transbordamento regional promovido pela economia brasileira na economia chinesa, ao produzir em setores como manufatura de computadores, eletrônicos e produtos ópticos. Para cada dólar produzido nesse setor no Brasil, gerou-se um multiplicador interregional sobre a economia chinesa de o,19 dólares em 2014. Na perspectiva setorial, nota-se também que os maiores estímulos dados pela produção da economia brasileira sobre a economia chinesa são no mesmo setor, isto é, quando o Brasil produz computadores, produtos eletrônicos e ópticos a sua dependência em relação à importação proveniente da China estão ligados ao mesmo setor. Diferentemente, quando a China produz, por exemplo, no setor de refino de petróleo, o principal produto brasileiro demandado é ligado à indústria extrativa.

Logo, pode-se inferir que o processo de integração produtiva é benéfico no curto prazo para ambos os países, devido ao volume de comércio transacionado por eles. No entanto deve-se atentar a respeito da desigualdade observada em relação à integração tecnológica, que indica uma nova forma de subordinação da economia brasileira no capitalismo global. Diante disso, reitera-se Cunha et al (2011) ao avaliarem que a integração entre os dois países não está associada ao posicionamento da China no mundo, mas sim às estratégias brasileiras no que diz respeito à condução do seu processo de industrialização e integração às cadeias globais de valor.

Desta forma, este estudo confirma por meio da análise insumo-produto que, embora os fluxos de comércio bilateral sejam proveitosos para ambos os países em termos agregados, a China tem se beneficiado mais do processo visto que tem políticas macroeconômicas e industriais claras e forjadas para o longo-prazo. Já o Brasil, como encontrou um arcabouço institucional propício ao processo de acumulação sem promover, necessariamente, o desenvolvimento da esfera industrial, não tem se atentado ao desenvolvimento de linkages na economia.

Este arcabouço fica explicitado de forma robusta ao avaliar os estímulos inter-regionais promovidos pelas economias, na medida em que estes são muito mais proveitosos para a economia chinesa. Com isso, defende-se que se não forem feitas mudanças, o Brasil pode se sujeitar a uma nova forma de dominação e atrasar, mais uma vez, sua oportunidade de promover de forma ativa e não subordinada seu processo de desenvolvimento econômico. 
Referências

ACIOLY, L. et al. As relações bilaterais Brasil-China: a ascensão da China no sistema mundial e os desafios para o Brasil. 2011

ALTEMANI DE OLIVEIRA, H. Brasil e China: uma nova aliança não escrita? Revista Brasileira de Política Internacional, v. 53, n. 2, 2010.

BAUMANN, Renato; CEPAL, N. U. Brasil: uma década em transição. 1999.

AREND, Marcelo. A industrialização do Brasil ante a nova divisão internacional do trabalho. Texto para Discussão, Instituto de Pesquisa Econômica Aplicada (IPEA), 2015.

BECARD, D. S. O que esperar das relações Brasil-China? Revista de Sociologia e Política, v. 19, n. Supl., 2011.

BRESSER-PEREIRA, L. C.; MARCONI, N. Doença holandesa e desindustrialização. Valor Econômico, v. 25, 2009.

BRESSER-PEREIRA, Luiz Carlos; MARCONI, N. Existe Doença Holandesa no Brasil? In: BRESSERPEREIRA, L. C. (Org.). Doença holandesa e indústria (coletânea). Rio de Janeiro: Editora FGV, 2010.

BRESSER-PEREIRA, Luiz Carlos (2010). Brasil vive desindustrialização. Folha de S. Paulo, 2010.

CANO, W. A desindustrialização no Brasil. Economia e Sociedade, Campinas, v. 21, Número Especial, p. 831-851. 2012.

CARVALHO, Veridiana Ramos da Silva. A restrição externa e a perda de dinamismo da economia brasileira: investigando as relações entre estrutura produtiva e crescimento econômico. 2007.

CORREAA, L. M.; PINTO, E. C.; CASTILHO, M. Mapeamento dos padrões de atuação dos países nas Cadeias Globais de Valor e os ganhos em termos de mudança estrutural. Texto para discussão. Rio de Janeiro, 2016.

CUNHA, A. M.; BICHARA, J. S.; MONSUETO, S. E.; LELIS, M. T. C. Impactos da ascensão da China sobre a economia brasileira: comércio e convergência cíclica. Rev. Econ. Contemp., Rio de Janeiro, v. 15, n. 3, p. 406-440, 2011.

DE NEGRI, F. Conteúdo tecnológico do comércio exterior brasileiro: o papel das empresas estrangeiras. Texto para discussão - IPEA, 2005.

DIAS, F. A. R; PORSSE, A. A.; DE OLIVEIRA G.Cadeias Globais De Valor E Complexidade: Uma Análise Sobre A Geração De Emprego No Brasil Para O Período 1995-2011 Pelo Método De Decomposição De Miyazawa. In: Anais do XLIII Encontro Nacional de Economia [Proceedings of the 43rd Brazilian Economics Meeting]. 2016.

DIEGUES, A. C.; ROSSI, C. G. Além da desindustrialização: transformações no padrão de organização e acumulação da indústria em um cenário de 'Doença Brasileira'. Texto para discussão. Instituto de Economia da Unicamp. 2017.

FILGUEIRAS, L. A natureza do atual padrão de desenvolvimento brasileiro e o processo de desindustrialização. Relatório de Pesquisa. Centro Celso Furtado, Rio de Janeiro, 2012. 
GEREFFI, G. Development models and industrial upgrading in China and Mexico. European Sociological Review, v. 25, n. 1, p. 37-51, 2009.

GEREFFI, G. Promessa e desafios do desenvolvimento. Tempo social, v. 19, n. 1, p. 223-248, 2007.

MASIERO, G.; COELHO, D. B. A política industrial chinesa como determinante da estratégia going global. Revista de Economia Política, v. 34, n. 1, 2014.

MÓDOLO, D. B.; HIRATUKA, C. Impacto da concorrência chinesa em terceiros mercados: uma análise por regiões e por categorias tecnológicas. Textos para discussão, Ministério da fazenda, n. 003, 2012.

MORAIS, I. N. Cadeias produtivas globais e agregação de valor: a posição da China na indústria eletroeletrônica de consumo. 2012.

MORCEIRO, P. C. Desindustrialização na economia brasileira no período 2000-2011: abordagens e indicadores. Dissertação (Mestrado). Universidade Estadual Paulista "Júlio De Mesquita Filho" (UNESP), Departamento De Economia. Araraquara, 2012.

MORCEIRO, P. et al. Conteúdo Importado na Produção Industrial e na Demanda Final do Brasil Recente: uma proposta de indicadores de importação e de conteúdo nacional/estrangeiro. In: Anais do XL Encontro Nacional de Economia ANPEC-Associação Nacional dos Centros de Pós graduação em Economia, 2014.

NASSIF, A. Há evidências de desindustrialização no Brasil? Brazilian Journal of Political Economy, vol. 28, no 1 (109), pp. 72-96. 2008

NONNENBERG, M. B., LEVY, P. M., DE NEGRI, F., \& COSTA, K. P. D. O crescimento econômico e a competitividade chinesa. Instituto de Pesquisa Econômica Aplicada. Rio de Janeiro, 2008.

NONNEMBERG, M. J. B.; MESENTIER, A. Is China only assembling parts and components? The recent spurt in high tech industry. Revista Economia Contemporânea. Rio de Janeiro, v. 16, n.2:.287-315. 2012.

OECD. Structural Adjustment and Economic Performance. Paris: Organization for Economic Cooperation and Development. 1987.

OREIRO, J. L.; FEIJO, C. L. Desindustrialização: conceituação, causas, efeitos e o caso brasileiro. Revista de Economia Política, vol. 30, no 2 (118), pp. 219-232. 2010

PALMA, J. G. Quatro fontes de desindustrialização e um novo conceito de doença holandesa. Trabalho a ser apresentado na Conferência de Industrialização, Desindustrialização e Desenvolvimento organizada pela FIESP e IEDI, Centro Cultural da FIESP. 2005.

PEREIRA, C.; NEVES, J. A. C. Brazil and China: South-South Partnership or North-South Competition? POLICY PAPER Number 26. 2011.

PINHEIRO, Maurício Canêdo et al. A urgente necessidade do fortalecimento da competitividade industrial brasileira: reflexão inicial sobre o papel da produtividade e da acumulação de capacidades tecnológicas inovadoras.

Technological Learning and Industrial Innovation Working Paper Series, n. 1, 2015. 
ROWTHORN, R; RAMASWANY, R. Growth, Trade and Deindustrialization. IMF Staff Papers, Vol. 46, N.1. 1999.

SARTI, Fernando; LAPLANE, Mariano F. O investimento direto estrangeiro e a internacionalização da economia brasileira nos anos 1990. Economia e Sociedade, v. 11, n. 1, p. 63-94, 2002.

SARTI, Fernando; HIRATUKA, Célio. Assimetrias no processo de internacionalização da economia brasileira no Século XXI. O Futuro do Desenvolvimento, p. 152-181, 2016.

SARTI, F.; HIRATUKA, C. Indústria mundial: mudanças e tendências recentes. Campinas: Unicamp. IE, 2010. 34p. Texto para Discussão, n.186, 2010.

STURGEON, T. et al. O Brasil nas cadeias globais de valor: implicações para a política industrial e de comércio ["Brazil in Global Value Chains: Implications for Industrial Polic yand Trade"]. Revista Brasileira de Comércio Exterior, 2013.

TREGENNA, F. Characterizing deindustrialization: an analysis of changes in manufacturing employment and output internationally. Cambridge Journal of Economics, vol. 33, pp. 433-466, 2009.

Recebido em 12.11.18

Aprovado em 19.06.19 
Anexo 1: Multiplicadores inter-regionais Brasil-China e China-Brasil para os anos 2000 e 2014

\begin{tabular}{|c|c|c|c|c|c|c|c|c|c|}
\hline \multirow{2}{*}{ Indústria } & \multicolumn{2}{|c|}{ MR BR-CN } & \multicolumn{2}{|c|}{ MR CN-BR } & \multirow[t]{2}{*}{ SERVIÇOS } & \multicolumn{2}{|c|}{ MR BR-CN } & \multicolumn{2}{|c|}{ MR CN-BR } \\
\hline & 2000 & 2014 & 2000 & 2014 & & 2000 & 2014 & 2000 & 2014 \\
\hline \multicolumn{10}{|c|}{ TECNOLOGIA INTENSIVA EM RECURSOS NATURAIS } \\
\hline Extrativa mineral & 0,001 & 0,011 & o,ooo & 0,002 & $\begin{array}{l}\text { Eletricidade, gás e } \\
\text { fornecimento de ar } \\
\text { condicionado e vapor }\end{array}$ & 0,001 & 0,012 & 0,001 & 0,002 \\
\hline Alimentos, bebidas e tabaco & 0,001 & o,oo6 & 0,001 & 0,009 & $\begin{array}{l}\text { Coleta, tratamento e } \\
\text { fornecimento de água }\end{array}$ & 0,001 & 0,007 & 0,000 & o,ooo \\
\hline Coque e refino de petróleo & 0,003 & o,oo8 & 0,001 & 0,007 & Construção & 0,001 & 0,023 & 0,001 & 0,001 \\
\hline $\begin{array}{c}\text { Madeira e de produtos de madeira } \\
\text { e cortiça, exceto móveis; fabricação } \\
\text { de artigos de palha e materiais } \\
\text { trançáveis }\end{array}$ & 0,001 & 0,010 & 0,001 & 0,001 & $\begin{array}{l}\text { Comércio e reparo de } \\
\text { automóveis e motocicletas }\end{array}$ & 0,000 & 0,009 & 0,000 & o,ooo \\
\hline $\begin{array}{l}\text { Fabricação de outros produtos } \\
\text { minerais não metálicos }\end{array}$ & 0,001 & o,o17 & 0,001 & 0,002 & $\begin{array}{l}\text { Comércio por atacado, } \\
\text { exceto veículos a motor e } \\
\text { motocicletas }\end{array}$ & 0,000 & 0,003 & o,o01 & 0,001 \\
\hline \multicolumn{5}{|c|}{ TECNOLOGIA INTENSIVA EM ESCALA } & $\begin{array}{c}\text { Comércio a varejo, exceto } \\
\text { veículos a motor e } \\
\text { motocicletas }\end{array}$ & 0,000 & 0,003 & o,o01 & 0,001 \\
\hline Papel e produtos de papel & 0,001 & $\mathrm{o}, 017$ & 0,001 & o,006 & Transporteterrestre & 0,001 & 0,007 & 0,000 & o,ooo \\
\hline Impressão e reprodução de mídia & 0,003 & 0,024 & 0,001 & 0,005 & Transporte aquático & 0,001 & 0,004 & o,ooo & o,ooo \\
\hline Química e produtosquímicos & 0,004 & 0,038 & o,oo1 & o,001 & Transporte aéreo & 0,001 & 0,005 & o,oo1 & o,ooo \\
\hline Borracha e produtosplásticos & 0,004 & 0,041 & o,ooo & 0,001 & $\begin{array}{l}\text { Armazenagem e atividades } \\
\text { de apoio ao transporte }\end{array}$ & 0,000 & 0,003 & 0,001 & 0,002 \\
\hline Metais básicos & 0,001 & o,o17 & 0,001 & 0,003 & $\begin{array}{c}\text { Atividades de alojamento e } \\
\text { serviços de alimentação }\end{array}$ & 0,000 & 0,004 & 0,001 & 0,002 \\
\hline $\begin{array}{l}\text { Fabricação de veículos a motor, } \\
\text { reboques e semi-reboques }\end{array}$ & 0,001 & 0,034 & 0,001 & o,ooo & Publicidade & 0,002 & 0,004 & o,ooo & o,ooo \\
\hline Equipamentos de transporte & 0,001 & 0,038 & o,ooo & 0,000 & $\begin{array}{l}\text { Produção de filmes, vídeos e } \\
\text { programas de televisão, } \\
\text { gravação de som e edição de } \\
\text { música; programação }\end{array}$ & 0,001 & 0,010 & o,ooo & o,ooo \\
\hline \multicolumn{5}{|c|}{ TECNOLOGIA INTENSIVA EM TRABALHO } & Telecomunicação & o,ooo & 0,003 & o,ooo & o,ooo \\
\hline Fabricação de móveis & 0,002 & o,049 & 0,001 & 0,001 & $\begin{array}{c}\text { Programação de } \\
\text { computadores, consultoria e } \\
\text { atividades relacionadas; } \\
\text { atividades de serviço de } \\
\text { informações } \\
\end{array}$ & 0,001 & 0,014 & o,ooo & 0,001 \\
\hline Têxtil e produtostexteis & 0,002 & 0,084 & 0,001 & 0,004 & $\begin{array}{l}\text { serviços financeiros, exceto } \\
\text { seguros e fundos de pensão }\end{array}$ & 0,000 & 0,002 & o,ooo & o,ooo \\
\hline $\begin{array}{l}\text { Produtos de metais, exceto } \\
\text { máquinas e equipamentos }\end{array}$ & 0,002 & 0,031 & 0,001 & 0,001 & Atividades imobiliárias & o,ooo & 0,001 & 0,001 & o,ooo \\
\hline \multicolumn{5}{|c|}{ TECNOLOGIA DIFERENCIADA } & $\begin{array}{l}\text { Atividades jurídicas e } \\
\text { contábeis; consultoria e } \\
\text { gestão }\end{array}$ & 0,001 & 0,005 & 0,001 & 0,001 \\
\hline Máquinas e equipamentos & 0,002 & 0,071 & o,ooo & 0,001 & $\begin{array}{l}\text { Arquitetura e engenharia; } \\
\text { teste técnico e análises }\end{array}$ & 0,001 & 0,017 & o,ooo & o,ooo \\
\hline $\begin{array}{l}\text { Computadores, produtos } \\
\text { eletrônicos e óticos }\end{array}$ & 0,014 & 0,189 & o,ooo & o,ooo & $\begin{array}{c}\text { Pesquisa e desenvolvimento } \\
\text { científico }\end{array}$ & 0,001 & 0,003 & 0,000 & 0,001 \\
\hline Equipamentos elétricos & 0,005 & o,o74 & 0,001 & 0,001 & $\begin{array}{c}\text { serviços administrativos e } \\
\text { de apoio }\end{array}$ & o,001 & 0,009 & o,ooo & 0,002 \\
\hline \multicolumn{5}{|c|}{ TECNOLOGIA BASEADA EM CIÊNCIA } & Educação & o,ooo & 0,004 & o,ooo & 0,001 \\
\hline \multirow[t]{2}{*}{$\begin{array}{l}\text { Produtos farmacêuticos básicos e } \\
\text { preparações farmacêuticas }\end{array}$} & 0,002 & 0,025 & 0,001 & 0,005 & Saúde e trabalho social & 0,001 & 0,014 & o,ooo & o,ooo \\
\hline & & & & & Outras atividades de serviço & 0,001 & 0,013 & o,ooo & 0,001 \\
\hline
\end{tabular}

